Linking effort and fishing mortality in a mixed fisheries model comparing linear versus non-linear assumptions

Thøgersen, Thomas Talund; Hoff, Ayoe; Frost, Hans Staby

Published in:

Fisheries Research

DOI:

10.1016/j.fishres.2012.04.015

Publication date:

2012

Citation for published version (APA):

Thøgersen, T. T., Hoff, A., \& Frost, H. S. (2012). Linking effort and fishing mortality in a mixed fisheries model: comparing linear versus non-linear assumptions. Fisheries Research, 127-128, 9-17.

https://doi.org/10.1016/j.fishres.2012.04.015 


\title{
Linking effort and fishing mortality in a mixed fisheries model: Comparing linear versus non-linear assumptions ${ }^{1}$
}

\author{
T. Thøgersen ${ }^{\mathrm{a}}, \mathrm{A}$. Hoff $^{\mathrm{b}}, \mathrm{H}$ Frost $^{\mathrm{c}}$ \\ a University of Copenhagen, Institute of Food and Resource Economics \\ Rolighedsvej 25, DK - 1958 Frederiksberg C, Denmark, tel.: +45 353368 95, email: thth@foi.ku.dk, Corresponding \\ author \\ ${ }^{\mathrm{b}}$ University of Copenhagen, Institute of Food and Resource Economics \\ Rolighedsvej 25, DK - 1958 Frederiksberg C, Denmark, tel.: +45 3533 68 96, email: ah@foi.ku.dk. \\ ${ }^{\mathrm{c}}$ University of Copenhagen, Institute of Food and Resource Economics, \\ Rolighedsvej 25, DK - 1958 Frederiksberg C, Denmark, tel.: +45 353368 93, email: hf@foi.ku.dk.
}

\section{Abstract}

Since the implementation of the Common Fisheries Policy of the European Union in 1983, the management of EU fisheries has been enormously challenging. The abundance of many fish stocks has declined because too much fishing capacity has been utilised on healthy fish stocks. Today, this decline in fish stocks has led to overcapacity in many fisheries, leading to incentives for overfishing. Recent research has shown that the allocation of effort among fleets can play an important role in mitigating overfishing when the targeting covers a range of species (multispecies-i.e., so-called mixed fisheries), while simultaneously optimising the overall economic performance of the fleets. The so-called FcubEcon model, in particular, has elucidated both the biologically and economically optimal method for allocating catches-and thus effort-between fishing fleets, while ensuring that the quotas are not exceeded. Until now, the FcubEcon modelling approach has assumed that there is a simplified linear relationship between effort and fishing mortality. The present study introduces an extension of the FcubEcon model, the so-called SOMER model, that allows this relationship to be non-linear by linking the biological catch equation with the economic production function. Furthermore, the SOMER model relaxes the assumption of the joint production of fishing metiers, unique and separately defined sub-fleets, to allow for more detail regarding the flexibility to target specific groups of species. Thereby, the SOMER model enables the managers to assess the alternative management scenarios more accurately than the existing models.

Key words:

Bioeconomic model; Effort allocation; Multi species fisheries; Non joint production; Non linearity

\footnotetext{
1 The reference of the printed version is: Thøgersen TT, Hoff A \& Frost HS (2012): Linking effort and fishing mortality in a mixed fisheries model : comparing linear versus non-linear assumptions. Fisheries Research 127-128: 9-17.

The definitive version is available at: http://www.sciencedirect.com/science/article/pii/S0165783612001440 or via DOI: 10.1016/j.fishres.2012.04.015
} 
Institute of Food and Resource Economics

University of Copenhagen

This is a post-print version of an article published in Fisheries Research

\section{Introduction}

EU fisheries management is based on single species stock assessments (Frost and Andersen, 2006; Vinther et al., 2004); fish stocks are assessed individually by the International Council for the Exploration of the Sea (ICES), which makes projections of future stock development under a range of assumptions about future fishing mortality. Based on these projections, Total Allowable Catches (TACs) are proposed and the associated socioeconomic implications of these TACs and the corresponding stocks are projected and evaluated by the Scientific, Technical and Economic Committee for Fisheries (STECF), which makes recommendations for the single species TACs. Then, the European Commission makes recommendations on the TACs to the Council of Ministers. Each year at the Council, the final TACs are agreed upon by the Ministers of the EU member states and divided among them through the member state "Relative Stability" principle as single species quotas $^{2}$. These quota limitations appear to be a practical management tool, but they often have shortcomings in multi-species fisheries because the fleets and fishing metiers exhaust the singlespecies quotas at different rates, which can lead to illegal landings, discards or the loss of fishing opportunities (Pascoe et al., 2007; Vinther et al., 2004). With the introduction of the 2002 reform of the Common Fisheries Policy, effort restrictions, in the form of capacity and sea days, have therefore been given more weight alongside quota control (EC, 2002). Sea-days restrictions combined with quota control were implemented by the European Commission in 2004 with the cod recovery plan in the North Sea, and they have been used as an effective way to protect specific species in the subsequent management plans (EC, 2010). One of the advantages of using limitations on sea days is that the vessels rarely have extra sea days once the main quota is filled, so the discards and illegal landings are reduced. A disadvantage of using the sea-days limitations is that catches of "healthy" stocks can be restricted more than necessary if the number of sea days is very low. The efficiency of the combined quota and effort control depends mainly on how restrictive the effort limit is (EC, 2009a) but also on the actual amount of discarding taking place.

For some time, the problem of the non-optimal combination of quota and effort limitations in mixed fisheries has been the focus of research directed at changing the management focus from a single species approach to an area- and fleet-based approach that integrates the need to protect individual fish stocks (Hoff and Frost, 2008; Ulrich et al., 2008). Recently, the EU FP6 project "AFRAME" (A Framework for Fleet and Area Based Fisheries Management) focused on the problem and established the Fleet and Fisheries Forecast model, Fcube, which provided mixedfisheries management advice while still accounting for the need to protect threatened stocks (AFRAME, 2009; Ulrich et al., 2011). FCube is specified in such a way that assumptions (and settings) for simulated management decisions are based on a combination of fleet catchability and fish-stock preservation considerations, i.e., on biological and fleet-specific factors. Fcube, however, did not include the economic behaviour of the fishermen in its original form. There is, nevertheless, a growing recognition among decision makers and scientists that an integrated

\footnotetext{
${ }^{2}$ Previously agreed percentage catch shares for each stock based on historical landings. For several stocks, the EU member states cannot decide on TACs themselves, but have to be in agreement with third-party countries such as Norway, Russia and the Faeroes.
} 
Institute of Food and Resource Economics

approach to the management of fishing resources must focus on the biological sustainability of the fish resources as well as on the economic sustainability of the fishing fleets (EC, 2009b; Polasky and Segerson, 2009; Tschirhart, 2009). Therefore, Hoff and Frost (2008) extended the Fcube model with an economic module, the FcubEcon model, which bases the final distribution of effort among the fishing fleets and metiers on maximising the gross profit (GP) of the fleet segments and metiers involved, with the possibility of keeping the catches of some severely depleted species below the single-species quotas if required.

Fcube, as well as FcubeEcon, assumes that fishing mortality ( $F$ ) is related to fishing effort (E) through the linear relationship $F=q E$, where the catchability coefficient $q$ is assumed to be constant. However, this relationship can be questioned from a theoretical as well as an empirical point of view (Coppola and Pascoe, 1998; Eide et al., 2003; Eide, 2007; Frost et al., 2009; Garza-Gil et al., 2003; Hannesson, 1983; van Oostenbrugge et al., 2008; Wilberg et al., 2010). Two implications of this relationship are 1) No crowding effect, i.e., the additional activity of one vessel does not affect the activity of the other vessels negatively, and therefore, there is no effect on the catchability; and 2) that the fishermen will choose their additional trips randomly from among the already existing trips instead of choosing the most profitable trip, as suggested by van Oostenbrugge et al. (2008). From a marginal perspective, this means that any additional effort is distributed equally among the historical trips. Using a non-linear relationship between effort and fishing mortality could be more realistic because it takes into account the possibility of crowding, which makes extra trips less profitable. Gillis (2003) describes crowding as a direct interference between vessels that reduces their efficiency, for example, when a trawler and its gear are blocking the way of another trawler. Furthermore, he explains that indirect interference, i.e., the disturbance of fish by vessels, can affect the catch per unit effort; for example, when mobile gears break up fish aggregations and potentially drive fish into accessible refuges. The effect of crowding is, furthermore, described by Rijnsdorp et al. (2000), who show that the catch rates of Dutch beam trawlers increased by $10 \%$ when the vessel density decreased by $25 \%$. Additionally, van Oostenbrugge et al. (2008) find a decreasing catch per unit effort in the Dutch Beam trawl fishery, which is explained by the economic decision to skip the less profitable trip first when the effort becomes restrictive. Based on a Cobb-Douglas function, van Oostenbrugge et al. (2008) use the equation $C=q * E^{\alpha}$, where effort (E) is the only dependent variable to describe the catches (C) (stock is assumed to be exogenous and constant) and $q$ is the catchability coefficient. Other authors have used a Cobb-Douglas function $\left(C=q * E^{\alpha} * B^{\beta}\right)$ with catches (C) as a function of effort (E) and stock (S) to estimate the exponents of effort and stock, respectively (Eide et al., 2003; Garza-Gil et al., 2003; Hannesson, 1983; Kronbak, 2005). Hannesson (1983) estimated the coefficients of the Cobb-Douglas function using data from the Lofoten fishery from 1950-1978 and found increasing returns to scale for various fleets. Garza-Gil et al. (2003) found decreasing returns to scale for the production factors in the Iberian hake trawl fishery ( $\alpha=0.59$ and $\beta=0.24$ ), while Eide et al. (2003) find evidence for the increasing returns to scale in the Norwegian bottom trawl fishery targeting cod. Eide et al. (2003) use catch, effort and stock data from 1971-1985, a period without binding quota restrictions, and for the best-performing model, the effort-catch elasticity is 
Institute of Food and Resource Economics

estimated at 1.23 and the stock-catch elasticity at 0.42. Likewise, Kronbak (2005) finds increasing returns to scale of the total production for bottom trawlers in the Baltic Sea with $\alpha=0.75$ and $\beta=0.64$. These papers indicate that the coefficients in a Cobb-Douglas function vary among trawler segments and that no general conclusions regarding returns to scale can be made. Where the above mentioned studies do show the existence of non-linearity between the effort (and stock) and the catches, the importance of using correctly specified Cobb-Douglas coefficients is still uncertain. This importance of correct specification will be investigated in this paper using an approach by Frost et al. (2009) that links the biological catch equation, relating catch to fishing mortality, with the economic Cobb-Douglas production function, relating catch to effort through a non-linear relationship.

An approach that links the biological and economic production functions is useful from an economic as well as a biological point of view because it builds a bridge between the biological and the economic approaches to estimating catches. However, to date, this approach has not been implemented in bioeconomic management assessment models. This paper thus presents an extension of the FcubEcon model, the SOMER model (Simulation and Optimisation Model for Effort Regulation in mixed fisheries), which includes a non-linear bioeconomic relationship between effort and fishing mortality.

Another shortcoming of the Fcube and FcubEcon models is that they both assume that all of the species taken by a given metier are caught together, i.e., that the vessel-metiers have joint production in output. The joint production technology is challenged by Thøgersen et al. (2006), who found that in some cases, only sub-groups of species are caught jointly, which implies that the species are caught non-jointly between these catch groups. More specifically, it was found that flatfish, Gadoids and Nephrops for Danish demersal trawlers in the North Sea suggest that there is non-joint production between the groups. This is taken into account in the SOMER model, which allows subgroups to be caught jointly within the group but non-jointly with the other subgroups. This extension allows for a more detailed view of the fishery and provides more refined management advice.

This paper thus presents the multi-fleet, multi-species SOMER management model for the optimal allocation of effort between fleet and metiers, taking into account single species advice in quota managed fisheries. As discussed above, the SOMER model is an extension of the Fcube and FcubEcon models, with the added possibility of including a non-linear bioeconomic relationship between effort and fishing mortality and more refined catch compositions for the individual metiers. These extensions enable managers to assess the management scenarios with more accuracy than is provided by the existing models and to propose combined quota and effort management scenarios that minimise the possibility of bycatch and discard. Although the main purpose of this paper is to illuminate the need for models to be specified correctly, this paper also illustrates the effect of allowing the quota mix to be optimised; this optimisation can be obtained by introducing international tradable quotas. 


\section{Model description}

The models applied in the present context are based on the FcubEcon bioeconomic model (Hoff et al., 2010) and include an economic assessment of each fleet as well as the optimisation of effort allocation between fleets and fisheries as a series of scenarios. The economic assessment determines the economic outcomes for the fisheries given various pre-set effort allocation scenarios between the fleets and metiers and based on the same catch compositions as in the base period. The optimisation determines the effort allocation among the fleets and metiers that will give the highest gross profit in the fisheries one year in the future given the restriction that no quota, which is determined by the fish stock assessments, can be exceeded ${ }^{3}$.

\subsection{The simulation analysis and scenarios}

The bioeconomic model is based on a non-linear relationship between the effort (E) and the fishing mortality (F). From a biological point of view, TACs and catches are traditionally estimated using proposed fishing mortalities, thus with the Baranov equation (Lassen and Medley, 2001) in which $\mathrm{F}$ is the control variable (see the left-hand side of Equation 1). Economists, however, estimate catches using a production technology, often basing these estimates on effort and biomass as production factors. Thus, to obtain direct correspondence between the biological and the economic estimates of catches, this paper proposes combining the biological Baranov equation and the economic Cobb-Douglas production function (the right-hand side of Equation 1$)^{4}$ when establishing a link between fishing mortality and fishing effort:

$B_{\mathrm{t}}\left[1-\exp \left(-F_{\mathrm{t}}-M\right)\right] \frac{F_{\mathrm{t}}}{F_{\mathrm{t}}+M}=L_{0}{\frac{E_{\mathrm{t}}}{E_{0}}}^{\alpha}{\frac{B_{\mathrm{t}}}{B_{0}}}^{\beta}$

Therefore, Equation 1 creates a direct non-linear link between the observed fishing effort $\left(E_{t}\right)$ used to catch a specific species in year $t$ and the estimated fishing mortality $\left(F_{\mathrm{t}}\right)$ in year $t$, given the estimated levels of stock biomass $\left(B_{\mathrm{t}}\right)$ in year $\mathrm{t}$ and the natural mortality $(\mathrm{M})$. $E_{0}$ is the effort used in the base period to obtain the landings $L_{0}$ in that period with stock $B_{0}$. The Cobb-Douglas coefficients $\alpha$ and $\beta$ represent the percentage effect for landings when the effort and the stock, respectively, change by one percent. There are constant returns to scale when the sum of $\alpha$ and $b$ equals one.

The SOMER model assesses the management options in a multi-fleet, multi-species context. The starting point is therefore $f=1, \ldots, F$ fleets, each divided into $n=1, \ldots, N$ metiers, catching $s=1, \ldots, S$ species. It is furthermore assumed that the $S$ species are caught jointly within $k=1, \ldots, K$ distinct

\footnotetext{
${ }^{3}$ Profit maximisation may not be the only driver for the skipper, but this is the assumption of both the FcubeEcon and the SOMER models.

${ }^{4}$ The right-hand side of equation 1 is a fairly standard Cobb-Douglas production function, although the inputs are ratios relative to the benchmark levels $E_{0}$ and $B_{0}$ rather than absolute levels.
} 
catch groups but that the species are caught non-jointly between the catch groups (sub-metier). In year $t$, an overall $\mathrm{TAC}_{\mathrm{t}, \mathrm{s}}$ is assigned to each species, corresponding to a target fishing mortality $F_{\mathrm{t}, \mathrm{s}}^{\mathrm{targ}}$. The TACs, and thus the target fishing mortalities, are divided between fleets and metiers according to historical landings:

$F_{t, f, n, s}^{\operatorname{targ}}=F_{t, s}^{\operatorname{targ}} \frac{L_{f, n, s}^{o}}{L_{S}^{O}}$

where $L_{f, n, s}^{0}$ is the historical landings of species $s$ caught by metier $n$ in fleet $f$, and $L^{0}{ }_{s}$ are the total historical landings of species $s$. For catch group $k$ belonging to metier $n$ in fleet $f$ to catch its quota, a certain effort $E_{\mathrm{t}, \mathrm{f}, \mathrm{n}, \mathrm{k}, \mathrm{s}}^{\mathrm{targ}}$ is needed, and these efforts are evaluated using equation (1), which, after rearranging, can be expressed as follows:

$$
\begin{aligned}
& B_{\mathrm{t}, \mathrm{s}} \quad 1-\exp \left(-F_{\mathrm{t}, \mathrm{s}}^{\mathrm{targ}}-M_{\mathrm{s}}\right) \frac{F_{\mathrm{t}, \mathrm{f}, \mathrm{k}, \mathrm{s}}^{\mathrm{targ}}}{F_{\mathrm{t}, \mathrm{s}}^{\mathrm{targ}}+M_{\mathrm{s}}}=L_{\mathrm{f}, \mathrm{n}, \mathrm{s}}^{0} \frac{E_{\mathrm{t}, \mathrm{f}, \mathrm{k}, \mathrm{k}, \mathrm{s}}^{\mathrm{targ}}}{E_{\mathrm{f}, \mathrm{n}, \mathrm{k}}^{0}} \alpha_{\mathrm{f}, \mathrm{n}, \mathrm{k}, \mathrm{s}} \frac{B_{\mathrm{t}, \mathrm{s}}}{B_{\mathrm{s}}^{0}}{ }^{\beta_{\mathrm{f}, \mathrm{k}, \mathrm{s}, \mathrm{s}}} ; s \in k \\
& E_{\mathrm{t}, \mathrm{f}, \mathrm{n}, \mathrm{k}, \mathrm{s}}^{\mathrm{targ}}=E_{\mathrm{f}, \mathrm{n}, \mathrm{k}}^{0} \frac{B_{\mathrm{t}, \mathrm{s}}^{0}}{L_{\mathrm{f}, \mathrm{n}, \mathrm{s}}^{0}} 1-\exp \left(-F_{\mathrm{t}, \mathrm{s}}^{\mathrm{targ}}-M_{\mathrm{s}}\right) \frac{F_{\mathrm{t}, \mathrm{n}, \mathrm{k}, \mathrm{s}}^{\mathrm{targ}}}{F_{\mathrm{t}, \mathrm{s}}^{\mathrm{targ}}+M_{\mathrm{s}}} \frac{B_{\mathrm{s}}^{0}}{B_{\mathrm{t}, \mathrm{s}}} \beta_{\mathrm{f}, \mathrm{n}, \mathrm{k}, \mathrm{s}}^{1} \alpha_{\mathrm{f}, \mathrm{n}, \mathrm{k}, \mathrm{s}} ; s \in k
\end{aligned}
$$

Here, $E_{\mathrm{f}, \mathrm{n}, \mathrm{k}}^{0}$ is the effort used by metier $n$ in fleet $f$ to catch the species belonging to group $k$ in the base period, and $E_{\mathrm{t}, \mathrm{f}, \mathrm{n}, \mathrm{k}, \mathrm{s}}^{\mathrm{targ}}$ is the effort needed in year $t$ for metier $n$ in fleet $f$ to catch species $s$ belonging to catch group $k$. Thus, individual target efforts are assigned to each species within group $k$. The metier catches the species within a group jointly, using only one effort, which leads to the well-known problem of non-compatible efforts in multi-species fisheries managed by single species quotas (Hoff et al., 2010; Pascoe et al., 2007; Vinther et al., 2004). It is therefore interesting to show the economic outcome of the different effort choice scenarios. One scenario is that the fishermen always use the effort corresponding to the least binding quota for all of the species belonging to group $k$, which will result in the discard of all species except for the species with the maximum quota or illegal landings. Another scenario is that the fishermen only keep fishing until the species that has the most restrictive quota in group $k$, has been caught, which will result in a fishery without discard or illegal landings, but also a fishery in which many stocks are underutilised. Therefore, the final effort, $E_{\mathrm{t}, \mathrm{f}, \mathrm{f}, \mathrm{k}}^{\mathrm{fina}}$ used by metier $\mathrm{n}$ in fleet $\mathrm{f}$ to catch the species belonging to group $\mathrm{k}$ is based on a function that restricts the target effort to be the same for all species within group $\mathrm{k}$ :

$E_{\mathrm{t}, \mathrm{f}, \mathrm{n}, \mathrm{k}}^{\mathrm{final}}=f E_{\mathrm{t}, \mathrm{f}, \mathrm{n}, \mathrm{k}, \mathrm{s}}^{\mathrm{targ}} s \in k$

Once the final number of days at sea used by metier $n$ in fleet $f$ to catch group $k$ is determined, the actual landings of each species by each metier are calculated using (cf. equation 3 ):

$L_{\mathrm{t}, \mathrm{f}, \mathrm{n}, \mathrm{s}}=L_{\mathrm{f}, \mathrm{n}, \mathrm{s}}^{0} \frac{E_{\mathrm{t}, \mathrm{f}, \mathrm{n}, \mathrm{s}}^{\mathrm{fina}}}{E_{\mathrm{f}, \mathrm{n}, \mathrm{k}}^{0}} \alpha^{\mathrm{f}, \mathrm{n}, \mathrm{s}} \frac{B_{\mathrm{t}, \mathrm{s}}}{B_{\mathrm{s}}^{0}} \beta_{\mathrm{f}, \mathrm{n}, \mathrm{s}} \quad ; s \in k$ 
This calculation yields the final total species landings, which can be compared with the TACs/quotas to investigate under/over exploitation:

$$
L_{\mathrm{t}, \mathrm{s}}=L_{f, n} L_{\mathrm{t}, \mathrm{f}, \mathrm{n}, \mathrm{s}}
$$

Furthermore, it is possible to evaluate the economic consequences of the fishery once the final efforts and landings are determined. The landings value (revenue) for each fleet is given by the following equation:

$$
\mathrm{R}_{\mathrm{t}, \mathrm{f}}=\mathrm{P}_{\mathrm{t}, \mathrm{f}, \mathrm{n}, \mathrm{s}} * \mathrm{~L}_{\mathrm{t}, \mathrm{f}, \mathrm{n}, \mathrm{s}}
$$

where $P_{\mathrm{t}, \mathrm{f}, \mathrm{n}, \mathrm{s}}$ is the price of species s obtained by fleet $\mathrm{f}$ when the species is caught in metier $\mathrm{n}$. The variable costs of the fishery are divided between the costs per effort unit, the costs per landed weight unit, and the costs per landing value.

$$
V C_{\mathrm{t}, \mathrm{f}}=e c_{\mathrm{f}} E_{\mathrm{n}}^{\mathrm{final}, \mathrm{n}}+l c_{\mathrm{f}} L_{\mathrm{n}, \mathrm{s}} L_{\mathrm{t}, \mathrm{f}, \mathrm{n}, \mathrm{s}}+c c_{\mathrm{f}} * R_{\mathrm{t}, \mathrm{f}}
$$

in which $\mathrm{ec}_{\mathrm{f}}$ is the cost per unit of effort used by fleet $\mathrm{f}$ to cover half of the variable costs used in the Data Collection Regulation (DCR) of the European Commission; $\mathbf{l c}_{\mathrm{f}}$ is the cost per landed kilo to cover the other half of the variable costs in DCR; and $\mathrm{cc}_{\mathrm{f}}$ is the fraction of the landing value used to cover the crew payments. The total gross profit (GP) taken by fleet $f$ in year $t$ is then given as follows:

$G P_{\mathrm{t}, \mathrm{f}}=R_{\mathrm{t}, \mathrm{f}}-V C_{\mathrm{t}, \mathrm{f}}$

A restriction included in the model is that all GPt,f,n,k of segment $f$ in metier $n$ and catch group $k$ for the assessment year $t$ must be zero or positive. This restriction is included because an economically rational fisherman will not go fishing if his expected earnings will not cover his variable costs. The total net profit $\mathrm{NP}_{\mathrm{t}, \mathrm{f}}$ taken by fleet $\mathrm{f}$ in year $\mathrm{t}$ is then calculated as follows:

$N P_{\mathrm{t}, \mathrm{f}}=R_{\mathrm{t}, \mathrm{f}}-V C_{\mathrm{t}, \mathrm{f}}-F C_{\mathrm{t}, \mathrm{f}}$

in which $\mathrm{FC}_{\mathrm{t}, \mathrm{f}}$ are the fixed costs of fleet $\mathrm{f}$ in year $\mathrm{t}$. Both the gross profit and the net profit can be used as economic indicators, but the gross profit is chosen here to be the preferred indicator because the net profit in some segments is negative, which complicates the comparability of certain results. 


\subsection{The optimisation analysis and scenarios}

The optimisation scenario is similar to the simulation scenario presented above in many regards. The optimisation can be seen as an additional effort allocation scenario, consistent with either choosing the minimum, the maximum or some third function of the individual species effort, as described in equation (4). In the optimisation case, the effort used in each metier $m$ by each fleet $f$ to catch group $\mathrm{k}$ is determined by optimising the total fishery GP, which is the sum of the individual fleet GPs given in equation (9), under some pre-determined restrictions. This allows the model to illustrate the economic performance of the fleets when these are able to optimise their quota mix, as would be expected in an ITQ management system. This case is also interesting for methodological reasons because it sets the results from the minimum scenario in perspective by comparing them to a scenario where the quota utilisation is optimised. Where the simulation model assumes that the fleets have constant effort shares, the optimisation model allows the effort to be allocated to the fleets with higher economic performance:

$\max _{\mathrm{E}_{\mathrm{t}, \mathrm{f}, \mathrm{n}, \mathrm{k}}} \quad{ }_{f} G P_{\mathrm{t}, \mathrm{f}}$

Subject to

Various restrictions

Using equations (5), (8) and (9), the total GP can be expressed as a (non-linear) function of the effort of the individual fleet, metier and groups of species via the landings and variable costs:

$$
G P_{\mathrm{t}, \mathrm{f}}=\mathrm{f}_{\mathrm{f}, \mathrm{n}, \mathrm{s}}\left(1-c c_{\mathrm{f}}\right) P_{\mathrm{t}, \mathrm{f}, \mathrm{n}, \mathrm{s}}-l c_{\mathrm{f}} L_{\mathrm{f}, \mathrm{n}, \mathrm{s}}^{0} \frac{E_{\mathrm{t}, \mathrm{f}, \mathrm{n}, \mathrm{k}}^{\mathrm{fina}}}{E_{\mathrm{f}, \mathrm{n}, \mathrm{k}}^{0}}{ }^{\alpha_{\mathrm{f}, \mathrm{n}, \mathrm{k}}} \frac{B_{\mathrm{t}, \mathrm{s}}}{B_{\mathrm{s}}^{0}} \beta_{\mathrm{f}, \mathrm{n}, \mathrm{k}, \mathrm{s}}-e c_{\mathrm{f}} E_{\mathrm{n}, \mathrm{k}}^{\mathrm{fina}, \mathrm{f}, \mathrm{n}, \mathrm{k}}
$$

The restrictions for the optimisations performed in this study are set such that the number of sea days per vessel for each catch group cannot exceed the maximum number of sea days per vessel, which, as a default, is set to 365 days. However, the maximum days at sea per vessel could potentially be lowered for technical or cultural reasons, such as bad weather conditions, maintenance, illness, weekends and holidays. A realistic default value is, however, difficult to set because the number of days at sea varies among fleets. For example, large trawlers with a large amount of invested capital are likely to operate on a two shift system to optimise the days at sea, while smaller netters are more likely to be a family business with one owner; thus, the vessel is likely to be utilised less. The model can easily change this assumption for each fleet segment, but for comparative purposes, the limit of 365 days is adequate. Another restriction in the model is that landings must not exceed the TACs.

\section{Data}

The model has been applied to the demersal fishery in the North Sea. The model currently includes nineteen demersal fleets, covering two Belgic fleets, two Dutch fleets, two Norwegian fleets, three English/Welsh fleets, four Scottish fleets, five Danish fleets and one fleet containing 
other vessels, but it is possible to extend the model to allow for more segments and/or to apply the model in other seas. In this case study, the effort is allowed to change only for two of these fleets, namely the Danish otter trawlers smaller than $24 \mathrm{~m}$ and the Danish otter trawlers larger than $24 \mathrm{~m}$, covering, respectively, 53 and 39 vessels. The $<24 \mathrm{~m}$ fleet is divided into 4 metiers, while the $>24 \mathrm{~m}$ fleet is divided into 5 metiers, each defined by different gears and mesh-sizes (see AFRAME (2009) for a further elaboration on the choice of metiers). The reason that the optimisation of effort is restricted to the trawler segments is that detailed information on the catch structure of these segments is available. Therefore, these segments are ideal for illustrating the new features of the model regarding non-joint production in output.

The model is programmed in Microsoft Excel ${ }^{\circledR}$ from Microsoft Office 2007, and the Excel Solver 2007 is used to run the optimisation. The inputs to the model are the fleet data, including the number of vessels, the catches, the catch composition and the days at sea for the relevant stocks and areas. Furthermore, the model includes the stock biomass estimates for the species included in the model, the fishing mortality, the natural mortality and the TAC. In addition, the cost and earnings data, including the variable costs such as fuel and maintenance, the fixed costs and the prices for species are required. The average cost and earnings data for 2004-2006 have been used as an input for the model to even out fluctuations.

Fleet data, including catches, species composition and days at sea, is obtained from the database by DTU-Aqua, while the cost and earnings data are obtained from the 2008 Annual Economic Report (STECF, 2010). Eight species are included in the case study. Six of these species are subject to stock assessments, namely cod, haddock, plaice, pollack, sole and whiting. Furthermore, two Nephrops functional units5, which are subject to catches by Danish demersal trawlers, are included in the case study; the first is Fladen Ground, situated northwest of Scotland, and the second is the "other group" representing the other functional units6.

The management year in the case study is 2007. The evaluations are based on the average biological and economic values from 2004-2006, representing the historic period. Table 1 shows the basic technical and economic data for the two fleets that are used in the model. The variable fishing costs (equation 8 ) include the crew payment, the sales cost, fuel, ice and provisions. The biological estimates of both natural mortality, fishing mortality and total stock biomass are used in the model. Furthermore, the total allowable catches (TACS) for the North Sea fleet and the sales price of fish are input parameters to the model. Table 2 gives an overview of the important biological and economic measures for each species.

\footnotetext{
${ }^{5}$ Nephrops are limited to muddy habitats and each habitat is therefore assessed as one stock, called a functional unit. There are eight functional units in the North Sea (ICES, 2008).

${ }^{6}$ The fishing mortalities for Nephrops (Other) are an average of all of the other functional groups, which are estimated in Hoff et al. (2010).
} 
Table 1: Average technical and economic vessel characteristics for the North Sea demersal fleet over the base period 2004-2006.

\begin{tabular}{lccccccc}
\hline & $\begin{array}{c}\text { Number } \\
\text { of vessels }\end{array}$ & $\begin{array}{c}\text { Days at } \\
\text { sea }\end{array}$ & $\begin{array}{c}\text { Gross } \\
\text { tonnage } \\
\text { GT }\end{array}$ & $\begin{array}{c}\text { Variable } \\
\text { fishing costs } \\
\text { ( } € / \text { day) }\end{array}$ & $\begin{array}{c}\text { Landings } \\
\text { costs } \\
\text { ( } € / \text { day) }\end{array}$ & $\begin{array}{c}\text { Crew } \\
\text { costs } \\
\text { ( } € / \text { day) }\end{array}$ & $\begin{array}{c}\text { Crew share } \\
\text { (\% of the } \\
\text { landings value) }\end{array}$ \\
\hline Demersal trawl 12-24m & 53 & 132 & 68 & 268 & 85 & 703 & 0.50 \\
Demersal trawl 24-40m & 39 & 248 & 216 & 764 & 231 & 1170 & 0.35 \\
\hline
\end{tabular}

Table 2: Biological, price and relative catch measures for species caught by Danish demersal trawlers

\begin{tabular}{|c|c|c|c|c|c|c|c|}
\hline & \multirow{2}{*}{$\begin{array}{c}\text { Fishing } \\
\text { mortality } \\
\text { rate } \\
\text { (average) }\end{array}$} & \multirow{2}{*}{$\begin{array}{c}\text { Natural } \\
\text { mortality } \\
\text { rate } \\
\text { (average) }\end{array}$} & \multirow{2}{*}{$\begin{array}{c}\text { Biomass } \\
2007 \\
\text { (1000 ton) }\end{array}$} & \multirow{2}{*}{$\begin{array}{c}\text { TAC } \\
2007 \\
\text { (1000 ton) }\end{array}$} & \multirow{2}{*}{$\begin{array}{c}\text { Sales prices } \\
2007 \\
\text { (euro/kg) }\end{array}$} & \multicolumn{2}{|c|}{$\begin{array}{l}\text { Catch Composition } \\
(\%)\end{array}$} \\
\hline & & & & & & $\begin{array}{c}\text { dem. trawl } \\
12-24 m\end{array}$ & $\begin{array}{c}\text { dem. trawl } \\
24-40 m\end{array}$ \\
\hline Cod & 0.34 & 0.57 & 337 & 20 & 1.88 & $13.0 \%$ & $12.6 \%$ \\
\hline Haddock & 0.14 & 1.17 & 1,563 & 55 & 1.02 & $4.0 \%$ & $9.9 \%$ \\
\hline Nephrops (Other) & n.a. & n.a. & n.a. & 3 & 7.26 & $12.1 \%$ & $13.6 \%$ \\
\hline Plaice & 0.44 & 0.1 & 470 & 50 & 1.84 & $54.9 \%$ & $22.7 \%$ \\
\hline Pollock & 0.27 & 0.2 & 577 & 31 & 0.61 & $14.1 \%$ & $37.9 \%$ \\
\hline Sole & 0.36 & 0.1 & 60 & 15 & 9.46 & $0.3 \%$ & $0.1 \%$ \\
\hline
\end{tabular}

${ }^{a}$ Data for haddock, plaice, pollack, sole and whiting from ICES (2007).

${ }^{\mathrm{b}}$ Data for Nephrops (Fladen) and Nephrops (other) are estimated by C. Ulrich (Hoff et al., 2010).

${ }^{c}$ The fishing mortality rate and the natural mortality rate are weighted with the stock biomass (tonnes) of each age group.

\section{Results and discussion}

The results of the case study illustrate the importance of the methodological issues presented in this paper. The results are thus only presented to the extent that they can contribute to the understanding of the consequences of (i) changing from a linear to a non-linear relationship between effort and fishing mortality and (ii) changing from an assumption of joint production 
technology to an assumption of non-joint production technology. Four sub-models have been investigated:

1. A joint fishery of all included species modelled using the traditional $F=q E$ linear relationship between fishing effort and fishing mortality (see Hoff et al. (2010) for an outline of the model)

2. A joint fishery of all included species modelled using the non-linear relationship between fishing mortality and fishing effort that is outlined in equation 3.

3. A non-joint fishery, divided into separate fisheries for flatfish, Gadoids and Nephrops, using the traditional $F=q E$ relationship between fishing effort and fishing mortality.

4. A non-joint fishery, divided into separate fisheries for flatfish, Gadoids and Nephrops, using the non-linear relationship between fishing mortality and fishing effort that is outlined in equation 3.

Sub-model 1 is the base model, i.e., the original FcubEcon model outlined in Hoff et al. (2010), while sub-model 4 corresponds to the entire SOMER model outlined in section 2 . Sub-models 2 and 3 represent the steps leading from sub-model 1 to sub-model 4.

In each sub-model, the economically optimal allocation of effort between fleets (equation 10) has been evaluated in the "optimal effort allocation scenario" (OEAS). Furthermore, a "minimum effort allocation scenario" (MEAS) has been assessed according to equations 3 and 4, which evaluates the minimum effort needed to catch any of the quotas for each metier (sub-models 1 and 2) or catch group (sub-models 3 and 4). The MEAS reflects the situation in which the fishermen stop fishing when the most restrictive quota of the species is reached. In reality, the fishermen are likely to keep fishing and to discard the species for which the quota is fully used as long as it is still profitable to do so (i.e., there are costs associated with discarding because fish must be sorted and thrown overboard). The minimum scenario should therefore be interpreted as a lower threshold for the short-term economic performance. Both the minimum and the optimum scenario ensure that no quotas are exceeded, thereby representing a fishery with no discarding.

The results, presented in Table 3, show the total gross profit aggregated over the two Danish fleets for the minimum and optimum scenario under different model assumptions. Using a non-joint output production technology and a non-linear relationship between $\mathrm{E}$ and $\mathrm{F}$ provides the highest gross profit at approximately 11 million euros. Limiting the flexibility of the production technology (sub-model 2) decreases the economic performance by approximately half. This reduction occurs because the fishermen are able to utilise a higher percentage of the quotas when catching the species non-jointly. However, this reduction will not take place if the value of the increased catches obtained by targeting specific species groups is less than the costs of the increased 
number of days spent at sea to catch the different species groups. This situation occurs with the linear models in which sub-model 3 has a lower gross profit than sub-model 1, even though submodel 3 has non-joint production. In general, the results show large differences depending on the assumptions. In particular, the degree to which the fishermen can target their catches in multispecies fisheries tends to play a major role in the outcome of fisheries management models in the North Sea when a non-linear relationship between $E$ and $F$ is assumed.

Table 3: Economic performance for the Danish North Sea demersal trawlers under different model assumptions.

\begin{tabular}{lcccc}
\hline & \multicolumn{4}{c}{ Gross profit (million euro) } \\
\cline { 2 - 5 } & Sub-model 1 & Sub-model 2 & Sub-model 3 & Sub-model 4 \\
\cline { 2 - 5 } Production technology & joint & joint & non-joint & non-joint \\
Relationship between E and F & linear & non-linear & linear & non-linear \\
\hline Minimum scenario & 3.60 & 5.84 & 2.09 & 11.05 \\
Optimum scenario & 6.43 & 6.96 & 5.17 & 11.65 \\
\hline
\end{tabular}

Apart from the differences in the sub-models, the results show, as expected, that the optimum scenarios in which the sea days are allocated to maximise the gross profit have a larger gross profit than the more static minimum scenario in which the relative distribution of sea days is constant. Another observation is that the models that have a linear relationship between $E$ and $F$ have a larger difference in the gross profits between the optimum and the minimum scenario than the non-linear models. The reason for this difference in the gross profit is based on the underlying assumption that discards can be prevented by an effort control system, which means that fishermen will generally have a lower quota utilisation. Depending on the sub-model and scenario type, there will be varying amounts of "underfishing," which is illustrated in Table 4 for the different species. The table shows that the linear models have an average lower quota utilisation than the non-linear models in the MEAS and that they therefore have a higher potential for improvement than the non-linear models.

Table 4: Levels of quota utilisation (landings divided by the quota) for both the minimum effort allocation scenario (MEAS) and the optimum effort allocation scenario (OEAS) for the four sub-models.

\begin{tabular}{|c|c|c|c|c|c|c|c|c|}
\hline \multirow{5}{*}{$\begin{array}{l}\text { Production technology } \\
\text { Link between E and F } \\
\text { Scenario type }\end{array}$} & \multicolumn{8}{|c|}{ Quota utilisation rate } \\
\hline & \multicolumn{2}{|c|}{ Sub-model 1} & \multicolumn{2}{|c|}{ Sub-model 2} & \multicolumn{2}{|c|}{ Sub-model 3} & \multicolumn{2}{|c|}{ Sub-model 4} \\
\hline & \multicolumn{2}{|c|}{ joint } & \multicolumn{2}{|c|}{ joint } & \multicolumn{2}{|c|}{ non-joint } & \multicolumn{2}{|c|}{ non-joint } \\
\hline & \multicolumn{2}{|c|}{ linear } & \multicolumn{2}{|c|}{ non-linear } & \multicolumn{2}{|c|}{ linear } & \multicolumn{2}{|c|}{ non-linear } \\
\hline & MEAS & OEAS & MEAS & OEAS & MEAS & OEAS & MEAS & OEAS \\
\hline Cod & 1.00 & 1.00 & 1.00 & 1.00 & 1.01 & 1.00 & 1.00 & 1.00 \\
\hline Haddock & 0.41 & 1.00 & 0.54 & 0.59 & 0.42 & 1.00 & 0.54 & 0.68 \\
\hline Nephrops-Fladen & 0.76 & 1.00 & 0.54 & 0.67 & 1.00 & 1.00 & 0.88 & 0.93 \\
\hline Nephrops-Other & 0.29 & 0.38 & 0.58 & 0.74 & 0.22 & 0.28 & 0.95 & 1.00 \\
\hline Plaice & 0.40 & 1.00 & 0.74 & 1.00 & 1.00 & 1.00 & 1.00 & 1.00 \\
\hline Pollock & 0.37 & 0.14 & 0.64 & 0.57 & 0.37 & 0.23 & 0.64 & 0.66 \\
\hline
\end{tabular}


Institute of Food and Resource Economics

University of Copenhagen

This is a post-print version of an article published in Fisheries Research

\begin{tabular}{lllllllll} 
Sole & 0.32 & 0.80 & 0.70 & 1.00 & 0.82 & 0.36 & 0.94 & 0.97 \\
Whiting & 0.25 & 0.66 & 0.45 & 0.54 & 0.25 & 0.05 & 0.45 & 0.55 \\
\hline Average & 0.48 & 0.75 & 0.65 & 0.77 & 0.64 & 0.62 & 0.80 & 0.85 \\
\hline
\end{tabular}

Furthermore, Table 4 shows that cod is the generally the most restrictive species for the fishermen, which means that the quota of cod is caught before (or simultaneously with) the other species' quotas. In turn, the other codfish such as haddock, pollack and whiting, which are highly correlated with the catch of cod, have a lower quota utilisation regardless of the production technology assumption. This implies that the protection of cod will cause a financial loss, not only because of the limited TAC of cod, but also because of the unused potential of the other codfish. This indirect pressure on cod is the reason that it was difficult to implement a North Sea Cod recovery program to begin with - and the discarding of small cod across the member state fleets over the past is probably the reason for cod's delayed recovery. Plaice is another species where quota utilisation is high, especially in the non-joint scenarios.

Apart from the observation that the non-linear models have a higher average quota utilisation than the linear models, it is interesting to note that the non-joint models have a higher average quota utilisation than the joint models and that the OEAS have a higher average utilisation than the MEAS. It is thus not surprising that the OEAS in model 4 has the highest quota utilisation and gross profit, while the MEAS in model 1 has the lowest quota utilisation and gross profit.

In the results presented above, the models that have a non-linear relationship between effort and fishing mortality are calculated with the effort-catch coefficient $(\alpha)$ at 0.59 and the stock-catch coefficient $(\beta)$ at 0.24 , as estimated by Garza-Gil et al. (2003). Similar coefficient levels are used by Frost et al. (2009) in the EIAA7 model, which is used to make economic interpretations of the ACFM8 advice. However, other studies have shown increasing returns to scale (Eide et al., 2003; Kronbak, 2005). Due to these differences, sensitivity analyses are performed to determine the robustness of the results using different $\alpha$ and $\beta$ coefficients in the non-linear models. The $\alpha$ coefficients are set to $0.2,0.4,0.6,0.8$ and 1 , while only three different values for the $\beta$ coefficients are presented $(0.2,0.6$, and 1$)$ for the sake of simplicity and a clearer overview. The estimates of gross profit based on the sensitivity test (coefficients set as listed above) are presented in Figure 1.

\footnotetext{
${ }^{7}$ Economic Interpretation of ACFM Advice

${ }^{8}$ ACFM is the Advisory Committee on Fishery Management
} 
Figure 1: Gross profit in million euros as a function of the effort-catch coefficient $(\alpha)$ for different stock-catch coefficients $(\beta)$. The relationship is shown for the minimum effort allocation scenarios (to the left) and the optimum effort allocation scenarios (to the right) for both the joint production models (upper part) and the non-joint production models (lower part). It should be noted that the joint production models have a different scale than the non-joint production models.

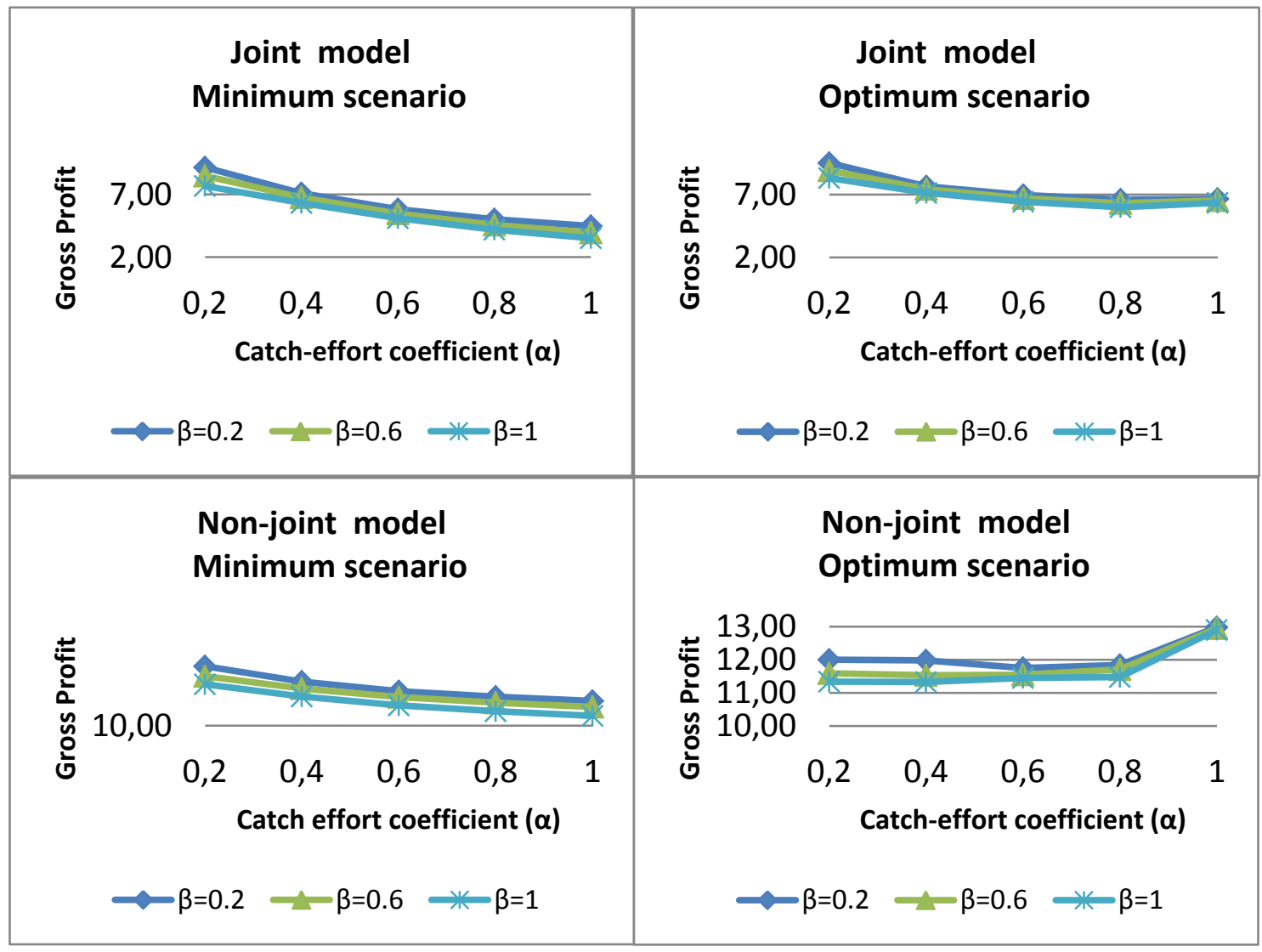

The relationship between the gross profit and the coefficient values is shown for the joint and the non-joint production technologies, respectively, and for both the minimum and the optimum scenarios, respectively (Figure 1 ). The gross profit for the minimum scenarios steadily decreases for increasing $\alpha$ and $\beta$. This decrease occurs because larger $\alpha$ and $\beta$ increase the effect of the landings for all $0<\alpha<1$ and $0<\beta<1$; see equation 5 . Because valuable stocks have decreased compared to the base period, the gross profit will also decrease with a larger $\beta$. Likewise, the effort is lower in the minimum model because the fishermen are not allowed to overfish any 
species, which results in a decreasing profit with a larger $\alpha$. The same trend is observed in the optimum scenarios, which can also be shown analytically; see equation (11). However, when $\alpha>0.4-0.6$ (the exact inflection point depends on the value of $\beta$ ), the gross profit increases with increasing $\alpha$ because the quotas are better utilised by being reallocated between metiers. The value of the increasing landings thus exceeds the costs of the extra sea days.

The upper part of Figure 1 shows the cases in which there is joint production in output. Comparing the optimum scenario (right) with the minimum scenario (left), shows that the optimum scenario produces marginally higher gross profits than the minimum scenario. The lower part of Figure 1 represents the non-joint fishery in which the species groups flatfish, Gadoids and Nephrops are caught in a separate metier. Additionally, in the non-joint case, the optimum scenario gives a higher gross profit. Comparing the "upper" joint sub-models with the "lower" non-joint models reveals that relaxing the strong assumption of joint production increases the gross profit by between $26 \%(\alpha=\beta=0.2)$ and $203 \%(\alpha=\beta=1)$. It should be noted that the increasing gross profit of $26 \%$ assumes decreasing returns to scale $(\alpha+\beta=0.4)$, whereas the increasing gross profit of $203 \%$ assumes increasing returns to scale $(\alpha+\beta=2)$. The main reason for increased gross profit by assuming non-joint production in outputs is the inclusion of increased catch flexibility, which makes it possible to utilise a larger proportion of the quotas.

To summarise, the results indicate that when simulated fishing in a model is based on assumptions that effort can be shifted, then the earnings will increase, compared to the case of a joint fishery. Furthermore, the results clearly indicate the importance of including detailed information on the catch flexibility in bioeconomic models because the absence of this information can lead to models that bias the results of the assessment. The results, furthermore, show that the optimum scenarios yield higher gross profits than the minimum scenarios. This indicates that a thoroughly considered effort allocation scheme can have a positive impact on the earnings of the fishermen. The optimum scenario thus represents a "room for improvement" scenario.

An interesting analysis is to compare the modelling results to the performance of the 2 fleets in the base period, which is estimated to be 6.21 million euros based on the historical data in 20042006. It is clear that the most flexible scenario 4, representing both the "non-joint" and "nonlinearity" assumptions, overestimates the actual performance of the fleet (both the MEAS as well as the OEAS). The actual performance is more in line with the performance modelled in scenario 2, which is based on a joint production function and a non-linear relationship between effort and fishing mortality. Here, the historical performance is between the MEAS (5.84 million euro) and the OEAS (6.96 million euros). This indicates that managers should use a non-linear model but assume joint production. Taking this as a starting point in a fishery restricted by quotas, the introduction of effort restrictions will prevent fishermen from discarding, and their gross profit will be reduced to 5.84 million euros, as in the MEAS. Then, effort allocation between fleets will be allowed in the OEAS, and the gross profit will increase to 6.98 million euros. 
Institute of Food and Resource Economics

The model presented in this paper builds on an underlying assumption of constant landings composition, which is based on the landings composition from the base period. The model assumes that the fishermen have not been distorting their optimal fishing patterns in the base period, i.e., that there are no quota-derived discards in the base period. This assumption is crucial because if the fishermen have been discarding in the base period, due to a lack of consistency between the available quotas and the catch composition, a bias in the catchability used in the model will result. The magnitude of the problem depends on the amount of discard of over-quota species. Estimates of discards for otter trawl in the North Sea are presented by Catchpole et al. (2005). The estimated discard for the Nephrops otter trawlers fishery constitutes between $45 \%$ and $59 \%$ of the landings, while the numbers are $20-48 \%$ for cod, $30-41 \%$ for haddock and $51-65 \%$ for whiting for the roundfish otter trawl fishery. While these measures might appear to be large, the figures constitute both the discard of undersized fish and the quota-derived discard, and a survey of the UK roundfish trawl fisheries in the North Sea indicate that a major part of the discards are undersized species ( $98 \%$ of cod, $87 \%$ of haddock and $97 \%$ of whiting) (Cappell, 2001). This indicates that the problem of whether the model reflects the true catch composition in the base year is relatively small.

The low level of quota-derived discards suggests that the fishermen choose to truncate their trip and return to port as soon as a quota is fully utilised. Another possibility is that the fishermen are non-compliant to the quotas and therefore land the marketable fish illegally (Cappell, 2001). The former is assumed in this paper and implies that there is no discard of quota species except for the catch of undersized fish. This scenario is likely if the managers impose a combination of quota and effort restrictions on the fishermen and the SOMER model can assist the manager to set the effort limits according to the quotas. In comparison, in management regimes where quotas are the main form for regulation, the fishermen with pure profit maximising behaviour would choose to discard the fully utilised quota species and land the other quota species as long as it is still profitable to do so. Fishermen that are financially constrained and/or able to justify their actions might even land the fish without the available quota (illegally). The possibilities of purchasing/leasing extra quotas or rolling over the quota to the following year are other ways to reduce the over-quota discards in the absence of effort restrictions.

The SOMER model is an important tool within EU fisheries management, where a complex mix of input and output controls are in place. This mix of management instruments makes it unclear which instruments are the limiting factors to fishing mortality in the complex of multi-fleet and multi-species fisheries. The use of both effort and quota limitations could lead the fishermen to take undesirable actions if the quota and effort restrictions are not carefully adjusted, each considering the other. For example, a fisherman may want to fish at a more distant fishing location at the end of the season with the expectation of catching the right mix of species to match the quotas. However, the fisherman is short on effort days and his only option is therefore to fish close to shore with, consequently, a large over-quota discard or the possible loss in income. These unfortunate situations could occur given combined quota and effort restriction management and 
could result in reducing the trust of the fishermen in the management regimes. It is therefore important that the quota and effort limitations are matched to create consistent pressure on fishing mortality, which is complicated by the setting of multiple fleets that catch multiple species and is subject to fluctuations in stock abundances over time. It is therefore important for managers to use multi-fleet, multi-species management assessment models such as SOMER that can provide advice on these matters.

As discussed in the introduction, it has been suggested by scientists, biologists and economists that there is a non-linear relationship between effort and fishing mortality in bioeconomic models. The effort-catch coefficients in the empirical studies range from 0.59-1.23. The estimates of the stock-catch coefficient were all below 1 , ranging from $0.24-0.89$, depending on the study. These estimates can be interpreted as indicating that the density of the stocks at the fishing ground increases by less than $1 \%$ when the total stock biomass increases by $1 \%$ (A. Eide et al., 2003). This is consistent with the empirical studies. Crecco and Overholtz (1990) found that the population of Georges Bank haddock appeared to aggregate at low levels of biomass and disperse at high levels of biomass. The same pattern is found for cod (Swain and Sinclair, 1994), while plaice and flounder do not have any significant distributional differences at the different levels of biomass in Kattegat and Skagerak (Casini et al., 2005). Another interpretation of the less than proportional increase in catch with increasing stock could be that the actual trawling time is only a fraction of the time spent at sea. Thus, if the Cobb-Douglas estimates are based on the total trip effort instead of only the trawling hours, these would, all other things being equal, be expected to provide a lower stock-catch coefficient. The large differences in economic performances with the changing effortcatch and stock-catch elasticities found in this study emphasise the importance of choosing these values correctly in management studies. More empirical studies are therefore needed to illuminate these issues.

Both the MEAS and the OEAS assume that the fishermen will avoid discarding if an effort control system is established. This assumption implies that the fishermen will not fully utilise all of their quotas and that most stocks will therefore be expected to increase. In the long term, this increase implies that the catchability will increase9, which could improve the economic performance in the future. The expected increase in stocks is therefore important to address so that the managers can weigh the social benefits and costs of potential management decisions. However, in this case study covering only 2 fleets in the North Sea, the absolute change in stocks is marginal and is not presented.

The assumption of no discard in the MEAS and the OEAS raises the question of whether the fishermen have incentives to avoid discard. Here, an issue is that the number of vessels is held

\footnotetext{
${ }^{9}$ In most cases, the catchability will increase when the stock abundance increases. However, there are exceptions to this rule, for example, clupeids with schooling behaviour. With such species, the catchability is found to increase when the stock abundance decreases as a result of a smaller habitat size that makes it easier to find the schools (Arreguín-Sánchez, 1996).
} 
constant in the SOMER model (sub-model 4), which means that the optimal number of sea days per vessel is 52 and 89 for the small and large Danish North Sea demersal trawlers, respectively. Because the maximum days at sea for a demersal trawler is much higher than these values, the capacity of the fleets is underutilised and thereby inefficient. A capacity underutilised fleet will have a high incentive to fish more than permitted, thus leading to a violation of the quotas and, in the long run, to stock depletion. It will be interesting to address this issue by extending the SOMER model to allow the amount of vessels in the fleet to vary. This extension would increase the utilisation of the fleet capacity and thereby the efficiency of each vessel. This type of extension will reflect an ITQ system, where the highly efficient vessels will buy the quotas from the less efficient vessels.

\section{Conclusion}

Management based on effort and capacity control relies heavily on a detailed understanding of the relationship between these factors and the fishing mortality if a successful outcome is to be obtained. In the present context, the SOMER model is developed and used to analyse two scenarios about how to allocate effort between fleets while continuing to maintain sustainable fisheries by limiting the total catches of the overexploited (threatened) species in the fleet's catch compositions. The minimum scenario is appropriate for short-run assessments of a non-discard fishery because it assumes that fishing vessels have the same fishing pattern as in previous years. The optimum scenario, however, is a long-run scenario in which vessels are able to shift into other fisheries where more profits are obtained but still under the constraint that no quotas are exceeded. The transition period towards an economically "optimal" fishery depends on the costs of reallocating the vessel, the degree of uncertainty in shifting to another fishery, the possible lack of skills to manage the new fishery and the assessments of the future stock- and price developments.

One strength of the SOMER model is that it creates consistency between the biological and economic approaches to estimating catch. This consistency is secured through the non-linear relationship between effort and fishing mortality rate, the form of which is introduced in this paper. Another strength of the model is that it allows different types of fishing patterns to be compared, i.e. the model can compare jointness in production with non-jointness. This allows the manager to use in-depth knowledge of a specific fishery to obtain more accurate measures of economic fleet performances, given specific management plans, or to use the range of results as a sensitivity analysis if no prior assumptions can be made. The model is useful for managers who wish to combine effort and quota regulation because it can provide a comparative estimate of the costs of different conservation policies.

\section{Acknowledgements}

We gratefully acknowledge two anonymous referees for constructive and comprehensive comments on the submitted draft version. 


\section{References}

AFRAME, 2009. A framework for fleet and area based fisheries management. Project no. 044168.

Sixth Framework Program, deliverable D. 1.2: Progress towards implementation of the fleet/fishery and indicator, frameworks in the North Sea using Fcube.

Arreguín-Sánchez, F., 1996. Cachability: a key parameter for fish stock assessment. Rev. Fish. Biol. Fish. 6, 221-442.

Cappell, R., 2001. Economic aspects of discarding. UK case study: Discarding by North Sea Whitefish Trawlers, Nautilus Consultants.

Casini, M., Cardinale, M., Hjelm, J., Vitale, F., 2005. Trends in cpue and related changes in spatial distribution of demersal fish species in the Kattegat and Skagerrak, eastern North Sea, between 1981 and 2003. ICES J. Mar. Sci. 62, 671-682.

Catchpole, T. L., Frid, C. L. J., Gray, T. S., 2005. Discards in North Sea fisheries: causes, consequences and solutions. Mar. Policy. 29, 421-430.

Clark, C. W., 2006. The Worldwide Crisis in Fisheries. Economic and human Behaviour. Cambridge University Press.

Coppola, G., Pascoe, S., 1998. A surplus production model with a non-linear catch-effort relationship. Mar. Resour. Econ. 13, 37-50.

Crecco, V., Overholtz, W. J., 1990. Causes of Density-Dependent Catchability for Georges Bank Haddock Melanogrammus-Aeglefinus. Can. J. Fish. Aquat. Sci. 47, 385-394.

EC, 2002. On the conservation and sustainable exploitation of fisheries resources under the Common Fisheries Policy. Council regulation (EC) No 2371/2002.

EC, 2009a. The Common Fishery Policy - A user's guide. Office for Official Publications of the European Communities.

EC, 2009b. GREEN PAPER: Reform of the Common Fisheries Policy. COM (2009)163 final.

EC, 2010. Fact Sheet on Multi-annual plans, [online]. [Last Update 11/08/2010]. URL:http://ec.europa.eu/fisheries/cfp/fishing_rules/multi_annual_plans/index_en.htm. European Commission. 
Eide, A., Skjold, F., Olsen, F., Flåten, O., 2003. Harvest Functions: The Norwegian Bottom Trawl Cod Fisheries. Mar. Resour. Econ. 18, 81-94.

Eide, A., 2007. Economic impacts of global warming: The case of the Barents Sea fisheries. Nat. Resour. Model. 20, 199-221.

Frost, H., Andersen, P., 2006. The Common Fisheries Policy of the European Union and fisheries economics. Mar. Policy. 30, 737-746.

Frost, H., Andersen, J. L., Hoff, A., Thøgersen, T., 2009. The EIAA Model: Methodology, Definitions and Model Outline. FOI Report no. 200. URL: http://www.foi.life.ku.dk/Publikationer/FOI_serier/Nummererede_rapporter.aspx\#2009

Garza-Gil, M. D., Varela-Lafuente, M. M., Suris-Regueiro, J. C., 2003. European hake fishery bioeconomic management (southern stock) applying an effort tax. Fish. Res. 60, 199-206.

Gillis, D. M., 2003. Ideal free distributions in fleet dynamics: a behavioral perspective on vessel movement in fisheries analysis. Can. J. Zool. 81, 177.

Gordon, H. S., 1954. The Economic Theory of a Common-Property Resource: The Fishery. Jour. Pol. Econ. 62, pp. 124-142.

Hannesson, R., 1983. Bioeconomic Production Function in Fisheries - Theoretical and EmpiricalAnalysis. Can. J. Fish. Aquat. Sci. 40, 968-982.

Hoff, A., Frost, H., 2008. Modelling economic response to harvest and effort control in North Sea cod fishery. Aquat. Living Resour. 21, 259-264.

Hoff, A., Frost, H., Ulrich, C., Damalas, D., Maravelias, C. D., Goti, L., Santurtun, M., 2010. Economic effort management in multispecies fisheries: the FcubEcon model. ICES J. Mar. Sci. 67, 1802-1810. ICES, 2007. Report of the Working Group on the Assessment of Demersal Stocks in the North Sea and Skagerrak (WGNSSK). ICES Document CM 2007/ACFM, 35, pp. 879.

ICES, 2008. Report of the ICES Advisory Committee 2008. Book 6, ICES Advice, 2008.

Kronbak, L. G., 2005. The Dynamics of an Open-access Fishery: Baltic Sea Cod. Mar. Resour. Econ. $19,459-479$.

Lassen, H., Medley, P., 2001. Virtual population analysis - A practical manual for stock assessment. FAO Fisheries Technical Paper 400. 
Pascoe, S., Koundouri, P., Bjorndal, T., 2007. Estimating targeting ability in multi-species fisheries: A primal multi-output distance function approach RID D-9710-2011. Land Econ. 83, 382-397.

Polasky, S., Segerson, K., 2009. Integrating Ecology and Economics in the Study of Ecosystem Services: Some Lessons Learned. Annu. Rev. Resour. Econ. 1, 409-434.

Rijnsdorp, A., Dol, W., Hoyer, M., Pastoors, M., 2000. Effects of fishing power and competitive interactions among vessels on the effort allocation on the trip level of the Dutch beam trawl fleet RID A-4217-2008. ICES J. Mar. Sci. 57, 927-937.

STECF, 2010. The 2010 Annual Economic Report on the European Fishing Fleet. EUR 24554 EN. Swain, D. P., Sinclair, A. F., 1994. Fish Distribution and Catchability - what is the Appropriate Measure of Distribution. Can. J. Fish. Aquat. Sci. 51, 1046-1054.

Thøgersen, T., Andersen, J. L., Hoff, A., 2006. CAFE - Work Package 5/6: Methodology and Case Studies. UCPH Contribution to the Final Report for the EU-FP6 project CAFE (Capacity, F and Effort). URL:http://ec.europa.eu/research/fp6/ssp/cafe_en.htm.

Tschirhart, J., 2009. Integrated Ecological-Economic Models. Annu. Rev. Resour. Econ. 1, 381-407. Ulrich, C., Reeves, S., Kraak, S., 2008. Mixed Fisheries and the Ecosystem Approach. ICES Insight. 45, 36-38.

Ulrich, C., Reeves, S. A., Vermard, Y., Holmes, S. J., Vanhee, W., 2011. Reconciling single-species TACs in the North Sea demersal fisheries using the Fcube mixed-fisheries advice framework. ICES J. Mar. Sci. 68, 1535-1547.

van Oostenbrugge, H. J. A. E., Powell, J. P., Smit, J. P. G., Poos, J., Kraak, S. B. M., Buisman, E. F. C., 2008. Linking catchability and fisher behaviour under effort management RID B-9940-2009. Aquat. Living Resour. 21, 265-273.

Vinther, M., Reeves, S., Patterson, K., 2004. From single-species advice to mixed-species management: taking the next step. ICES J. Mar. Sci. 61, 1398-1409.

Wilberg, M. J., Thorson, J. T., Linton, B. C., Berkson, J., 2010. Incorporating Time-Varying Catchability into Population Dynamic Stock Assessment Models. Rev. Fish. Sci. 18, 7-24. 